\title{
An agitation of contrary opinions
}

\author{
PETER TYRER
}

\begin{abstract}
Summary Those people who are dangerous often have personality disorders. Should these individuals be dealt with by criminal justice or mental health services? England (note not Scotland) has taken the mental health route with the Dangerous and Severe Personality Disorder Programme. Is this bold move wise or foolish? To answer this question we have both evidence and opinion - neither is conclusive.
\end{abstract}

Declaration of Interest P.T. is Editor of the British Journal of Psychiatry and has received a grant for the evaluation of aspects of the DSPD Programme. The decision to publish this supplement, and the peer review of its content, was made independently by other members of the Editorial Board. The views expressed here, and in the rest of the supplement, are those of the authors and not necessarily those of the Home Office or Department of Health (nor do they represent Government policy). The publication of this supplement was supported by the DSPD Programme but that played no part in the selection and review of the papers included.

The initials DSPD (dangerous and severe personality disorder) have only been with us for 7 years, and although the term is specific to services in England, it is becoming better known through international communication (Moran, 2001; Maden \& Tyrer, 2003; Fountoulakis \& Kaprinis, 2006). For those who have not yet ventured beyond the initials to the context, this supplement is an essential read. This is not a specious attempt to get you to read something you would otherwise ignore but an attempt to expose a range of important issues that have attracted a good deal of controversy, and no doubt will continue to do so, to fuller scrutiny. Reading this will help you to decide, or at least consider your previous opinions, about important questions in everyday practice, such as 'Is the care of those with severe personality disorder a responsibility for mental health services? Is dangerousness predictable?' and 'How do we protect society from those who pose a severe risk of violence?'

As a profession, psychiatry has not been slow to express its opinions about DSPD. The Home Office and Department of Health stress that it is not a diagnostic term but a description of a new programme to provide both specialised care for a small but important group and to protect the public from risk. Early on negative views outweighed positive views by a factor of 3 to 1 (Haddock et al, 2001), and among the concerns the ethical ones of detaining people for long periods were very prominent (Moran, 2001). Indeed, some have gone right back to the Hippocratic oath and questioned whether doctors might be abusing their position if they 'give patients, or recommend to them, an investigation or treatment which you know is not in their best interests' (Haddock et al, 2001). Others are more sanguine, believing that the concerns about doctors being granted unlimited powers over people's freedom is never likely to happen, or as Maden (2002) put it in the context of worries expressed by the philosophy of Michel Foucault, 'the experience of working in the National Health Service soon reduces one's ability to empathise with a man who worries about doctors taking over the world.'

There is genuine concern about the ethics of opting out of care for a needy group of individuals if we fail to address these problems, if we as clinicians refuse to treat people who are clearly unwell and distressed, we would be failing in our duty of care and pushing these vulnerable patients into the criminal justice system' (Mahapatra, 2001). On an even more positive note Mullen (2007) comments in this supplement that the DSPD Programme 'now represents a genuine attempt to address the psychological and interpersonal difficulties of recidivist violent offenders in a manner which it is hoped will decrease the damage these people do to others and to themselves.' However, you will note from the punctuation of his title that joining the three distinct entities remains a hypothesis, not a proof.

The group we are talking about is small (around 1 in less than 5000 of the relevant population). This translates to 350 people and we know that there are perhaps 7-10 times as many in prison. This remains a tiny proportion of the 2.2 million people in the UK who have personality disorders according to a nationwide survey (Coid et al, 2006), but one which is highly significant in political and social terms. There may be arguments over the best way of managing this small group but the need for management cannot be ignored, either in terms of public protection or in meeting their mental health needs. What is done in this area will no doubt have a significant impact on the broader development of personality disorder services.

In Scotland the introduction of legislation to cater for this group has been relatively smooth: the adoption of the MacLean Committee's recommendations of 'an order for lifelong restriction for offenders likely to pose a continuing and serious risk to the public' has avoided the complexities created by the term 'personality disorder' (Darjee \& Crichton, 2002). In England, Chiswick's prediction (2001) that 'the Government has created a personality disorder monster that the public wish to see slain and we can expect Members of Parliament dutifully to approve the legislation' has not yet taken a form that critics feared. However, the legal landscape in England and Wales has been transformed (Criminal Justice Act 2003) with the introduction in April 2005 of public protection sentences whereby indeterminate detention can be imposed on the basis of convictions for serious sexual or violent offences, with release, after the tariff period has been served, being dependent on the parole board being satisfied that the risk has reduced.

In Holland, as Maden (2007) reports in these pages, they have been quietly dealing 
with this problem in a different way for many years, and in Canada, that haven of good order and violence assessment capital of the world, they have pioneered assessment and treatment of this group ahead of all others, and we are pleased to report one of the core programmes in these pages (Wong et al, 2007).

The management and reduction of risk is central to the success of any Programme to prevent violence, and this has always been at the core of the DSPD Programme. The problem here is that we are not yet very good at prediction and are a long way from the film Minority Report in which the exact nature and timing of violent offences was identified by 'precogs' with advance knowledge. Our precogs are primitive and do not go much beyond basic demographic details and legal history (Buchanan \& Leese, 2006), and as a consequence we are likely to detain people for longer than might be necessary to address the needs of public protection (Buchanan \& Leese, 2001). The hope is that we are getting better at prediction, but it will take a long time to be sure. The best ways of measuring risk and personality disorder and the interpretation of the data are discussed at length in this supplement.

We are very pleased to be able to have all sides of this controversy exposed for the readers of the British Journal of Psychiatry to mull over at their leisure.

PETER TYRER, MD, Department of Psychological Medicine, Charing Cross Hospital, London W6 8RP, UK. Email: p.tyrer@imperial.ac.uk

Samuel Johnson, in his first dictionary of the English language, separated the word 'dispute' from 'controversy' as the former was 'commonly oral' whereas controversy, nicely defined as 'an agitation of contrary opinions', was 'in writing'. Whatever your interest in the subject of personality disorder or dangerousness we hope that you will allow yourself to be diverted into this controversy and be stimulated, informed and possibly edified.

\section{REFERENCES}

Buchanan, A. \& Leese, M. (200I) Detention of people with dangerous severe personality disorders: a systematic review. Lancet, 358, 1955-1959.

Buchanan, A. \& Leese, M. (2006) Quantifying the contributions of three types of information to the prediction of criminal conviction using the receiver operating characteristic. British Journal of Psychiatry, $\mathbf{1 8 8}$ $472-478$.

Chiswick, D. (200I) Dangerous severe personality disorder: from notion to law. Psychiatric Bulletin, $\mathbf{2 5}$ 282-283.

Coid, J., Yang, M., Tyrer, P., et al (2006) Prevalence and correlates of personality disorder in Great Britain. British Journal of Psychiatry, 188, 432-431.

Darjee, R. \& Crichton, J. H. M. (2002) The MacLean Committee: Scotland's answer to the 'dangerous people with severe personality disorder' proposals? Psychiatric Bulletin, 26, 6-8.

Fountoulakis, K. N. \& Kaprinis, G. S. (2006)

Personality disorders: new data versus old concepts. Current Opinion in Psychiatry, 19, 90-94.

Haddock, A.W., Snowden, P. R., Dolan, M., et al (200I) Managing dangerous people with severe personality disorder: a survey of forensic psychiatrists' opinions. Psychiatric Bulletin, 25, 293-296.

Maden, A. (2002) Review of Personality Disorder and Human Worth: Papers from a Conference Organised by the Board for Social Responsibility. British Journal of Psychiatry, I8I, 266-267.

Maden, A. (2007) Dangerous and severe personality disorder: antecedents and origins. British Journal of Psychiatry (suppl. 49), s8-sll.

Maden, A. \& Tyrer, P. (2003) Dangerous and severe personality disorder: a new personality concept from the United Kingdom. Journal of Personality Disorders, I7, 489-496.

Mahapatra, P. (200I) Mental Health Act reform: treatment of dangerous and severe personality disorder. Psychiatric Bulletin, 25, 486.

Moran, P. (200I) Dangerous severe personality disorder - bad tidings from the UK. International Journal of Social Psychiatry, 48, 6-10.

Mullen, P. E. (2007) Dangerous - and severe personality disorder - and in need of treatment. British Journal of Psychiatry (suppl. 49), s3-s7.

Wong, S. C. P., Gordon, A. \& Gu, D. (2007)

Assessment and treatment of violence-prone forensic clients: an integrated approach. British Journal of Psychiatry (suppl. 49), s66-s74. 